\title{
Application of lon Exchange Resin in the Advanced Treatment of Condensate Water
}

\author{
Xiaodan $\mathrm{Li}^{1, *}$, Shikun $\mathrm{Wu}^{1}$, Chunlei Kan ${ }^{1}$, Ye Zhang ${ }^{1}$, Yingbin Liang ${ }^{1}$, Guangzhi Cui ${ }^{1}$, Jiandong $\mathrm{Li}^{1}$ and Songlin Yang ${ }^{2}$ \\ ${ }^{1}$ Beijing Institute of Mechanical Equipment, Beijing 100039, China \\ ${ }^{2}$ Astronaut Center of China, Beijing 100094, China
}

\begin{abstract}
The advanced treatment of condensate water is important for efficient reuse of water resources, especially in confined space. In this work, a novel integrated process of ion exchange resins and activated carbon is proposed to remove various pollutants in condensate water. A fixed bed column of pre-treated basic anion exchange resin, acidic cation exchange resin, mixed ion exchange resins and modified activated carbon was applied to remove ionic pollutants, organic pollutants and adjust the $\mathrm{pH}$ value of output water. The effects of the types, amount ratios and the sequence of ion exchange resins were investigated using two types of condensate water. The results showed that the output water of the fixed bed column had an average TOC of 30 70 ppm, conductivity under $5 \mu \mathrm{S} / \mathrm{cm}, \mathrm{pH}$ value of $5 \sim 8$, which could meet the requirements of sanitary water. The saturated adsorption capacities of the basic anion exchange resin and the acidic cation exchange resin were calculated to be $0.87 \mathrm{~mol} / \mathrm{L}$ and $1.82 \mathrm{~mol} / \mathrm{L}$, respectively. Under the actual operating conditions, continuous dynamic test was carried out over a condensate water treatment module consisting of two adsorption columns and four exchange columns to evaluate its real service life.
\end{abstract}

\section{Introduction}

Condensate water is generated from a variety of sources in our daily life, including air conditioning system, food plant, chemical plant, greenhouse production, and also some particular environments such as hermetic area [1,2]. The hermetic area or cabin of biology laboratories and health laboratories is a very typical example of confined space, where the treatment and recovery of condensate water is a very important way to in-situ reuse the water resources and control the humidity simultaneously $[3,4]$. Condensate water mainly comes from the condensation of volatile gases and human metabolism as well. During condensation, various compounds derived from people breathing, skin perspiration, experimental operations and device running are introduced into water as pollutants, which have to be removed or treated for safety and water recovery. The typical organic pollutants in condensate water mainly include $\mathrm{C}_{1} \sim \mathrm{C}_{4}$ alcohols (methanol, ethanol, ethylene glycol, etc), acetone, aldehydes, organic acids (formic acid, acetic acid, etc) and some larger organic compounds such as caprolactam and dimethylformamide. The typical ionic pollutants include $\mathrm{Na}^{+}, \mathrm{K}^{+}, \mathrm{SO}_{4}{ }^{2-}, \mathrm{Cl}^{-}$, $\mathrm{NH}_{4}{ }^{+}$as well as $\mathrm{CO}_{3}{ }^{2-}$ and $\mathrm{HCO}_{3}{ }^{-}$caused by carbon dioxide dissolution [5]. The treatment and removal of the above pollutants has received a considerable attention because of its association with both safety and health problems.

In industry, there are numerous processes available for condensate water treatment, such as filtration, membrane, precipitation, coagulation, sedimentation, flotation, ion exchange, chemical adsorption, catalytic oxidation and electro-chemical techniques [6-8]. However, most of the existing processes or techniques are difficult to meet the needs of condensate water treatment in confined space, due to their disadvantages of high energy consumption, low purification efficiency, residual waste generation, high maintenance costs and limited processing capacity. Ion exchange resin is a kind of porous polymer of high molecular weight that contains groups which can be exchanged with ions in a solution with which it is in contact [9-10]. There are multiple types of ion exchange resins and they have been widely used in waste water treatment. Although the ion exchange method has the advantages of simple operation, high adsorption speed, less pollution, low energy consumption and high purity of output water [11], the application of traditional ion exchange method has been limited because of its low adsorption capacity and the leaching of the functional groups. Thus it is necessary to improve the adsorption capacity as well as the stability of ion exchange resins, while its combination with other efficient absorbents is promising to be used for condensate water treatment.

In this work, a novel integrated process of ion exchange resins and activated carbon is proposed for the advanced treatment of condensate water. A fixed bed column of self-treated basic anion exchange resin, acidic cation exchange resin, mixed ion exchange resins and modified activated carbon was applied to remove ionic

\footnotetext{
* Corresponding author: lixd1112@163.com
} 
pollutants, organic pollutants and adjust the $\mathrm{pH}$ value of output water. The effects of the types, amount ratios and the sequence of ion exchange resins were investigated using two types of condensate water samples. One sample mainly consisted of soluble sodium salts, acetic acid and carbonic acid, which was similar to human metabolism wastes. The other sample was more complicated with over twenty chemical components added, which was used to simulate experimental wastes from laboratories. The results showed that the fixed bed column had a good performance on treating both of the condensate water samples. The TOC, conductivity and $\mathrm{pH}$ value of its output water can meet the needs of sanitary water. The saturated adsorption capacities of both the basic anion exchange resin and the acidic cation exchange resin were calculated, which were higher than the commercial ones. Moreover, under the actual operating conditions, the continuous dynamic test was carried out on a condensate water treatment module consisting of two adsorption columns and four exchange columns to evaluate its real service life.

\section{Experimental}

\subsection{Materials}

The original strong acid cation exchange resins (Na type) and strong basic anion exchange resins $(\mathrm{Cl}$ type) were purchased from Rohm-Hass. The commercial acid cation exchange resins were pre-treated with hydrochloric acid and transferred to $\mathrm{H}$ type, while the strong basic anion exchange resins were pre-treated with sodium hydroxide and transferred to $\mathrm{OH}$ type. The mixed ion exchange resins were prepared by mixing the pre-treated cation exchange resins of $\mathrm{H}$ type and the anion exchange resins of $\mathrm{OH}$ type with a volume ratio of $3: 5$. The mixed ion exchange resins were fully stirred for $1 \sim 2 \mathrm{~h}$ to ensure that the two kinds of resins were thoroughly mixed. The pitch based activated carbon was provided by East China University of Science and Technology [12]. Typically, the activated carbon was pre-treated in ultrapure water with ultrasound for $24 \mathrm{~h}$ and then filtered by a $0.45 \mu \mathrm{m}$ strainer before use, which could remove the impurities absorbed in the pores of the activated carbon during its storage.

Two types of condensate water samples were prepared. For the simulation of condensate water collected from human metabolism wastes which was referred as Sample A, appropriate amounts of potassium chloride, ammonia and acetic acid were added into ultrapure water, then hydrochloric acid was added to adjust the $\mathrm{pH}$ value of the sample to $3 \sim 5$. The condensate water collected from experimental wastes and laboratories had a huge number of pollutants, therefore the simulation sample referred as Sample B was also prepared to simplify its analysis and calculations. The Sample B was prepared by dissolving three inorganic salts, twelve organic components as well as ammonia in ultrapure water, whose $\mathrm{pH}$ value was $8 \sim 9$. The detailed components of the Sample A and Sample B are summarized in Table 1. The ultrapure water was made by a UP water purification system (Milli-Q). All the chemicals were of analytical grade and purchased from Beijing Chemical Works.

Table 1. The components of condensate water samples.

\begin{tabular}{|c|c|c|c|}
\hline $\begin{array}{c}\text { Entr } \\
\mathrm{y}\end{array}$ & Component & $\begin{array}{c}\text { Content } \\
(\mathrm{mg} / \mathrm{L})\end{array}$ & $\begin{array}{c}\text { Sample } \\
\text { No. }\end{array}$ \\
\hline 1 & hydrochloric acid & 8.8 & Sample A \\
\hline 2 & acetic acid & 120 & Sample A \\
\hline 3 & ammonia & 4.5 & Sample A \\
\hline 4 & potassium salt & $5 \sim 10$ & Sample A \\
\hline 5 & potassium salt & 15 & Sample B \\
\hline 6 & sodium salt & 41 & Sample B \\
\hline 7 & $\mathrm{C}_{1} \sim \mathrm{C}_{3}$ alcohols & 165 & Sample B \\
\hline 8 & acetone or aldehydes & 15 & Sample B \\
\hline 9 & $\mathrm{C}_{1} \sim \mathrm{C}_{3}$ organic acid & 75 & Sample B \\
\hline 10 & $\begin{array}{c}\mathrm{C}_{6} \sim \mathrm{C}_{8} \text { organic } \\
\text { compounds }\end{array}$ & 60 & Sample B \\
\hline 11 & ammonia & 40 & Sample B \\
\hline
\end{tabular}

\subsection{Condensate water treatment}

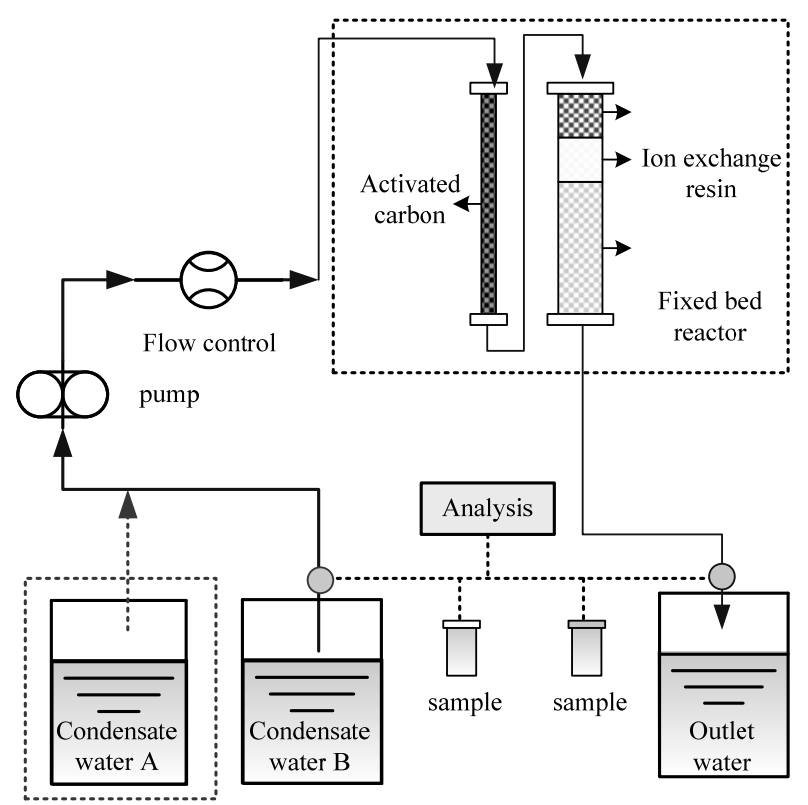

Fig.1. The process of the treatment of condensate water.

Experiments of condensate water treatment were carried out using fixed bed reactor. In a typical experiment, the pre-treated ion exchange resins were loaded into a quartz tube reactor (20 mm ID) in corresponding order to make an exchange column, which was compacted and filled with ultrapure water to push the air out of the tube. The activated carbon was loaded into a separate tube and put in front of the exchange column. Similarly, the activated carbon tube was also compacted and filled with ultrapure water to push the air out. The two tubes or columns were connected by flexible hoses which were corrosion resistant. To prevent 
different ion exchange resin layers blended, all of the columns were vertically fixed and the water sample always entered from the top and flowed out from the bottom. Before the experiment, the whole system was purged with ultrapure water for $30 \mathrm{~min}$ to get the baseline. As shown in Figure 1, the condensate water sample was introduced into the reactor by pump with a constant flow rate of $28 \mathrm{~mL} / \mathrm{min}$. The experiments were carried out under the atmospheric pressure and room temperature. The outlet water from reactor was regularly sampled and analyzed.

\subsection{Analytical method}

Both the condensate water samples and the outlet water were collected and detected for their conductivity, $\mathrm{pH}$ value and TOC contents. The $\mathrm{pH}$ value was detected using a pH meter (Mitler Toledo 700). The conductivity was detected using a conductivity meter (Mitler Toledo YSI3200). The TOC (total organic carbon) and TC (total carbon) of the water samples were analyzed using a Shimadzu TOC analyzer. The content of ammonia was detected by ion chromatography.

The saturated adsorption capacity of the strong basic anion exchange resin $Q_{\mathrm{A}}$ and the saturated adsorption capacity of the strong acidic cation exchange resin $Q_{\mathrm{B}}$ are calculated as follows:

$$
\begin{aligned}
& Q_{\mathrm{A}}=\left(V \times \sum q_{\mathrm{i}} C_{\mathrm{i}}\right) / L_{\mathrm{A}} \\
& Q_{\mathrm{B}}=\left(V \times \sum q_{\mathrm{j}} C_{\mathrm{j}}\right) / L_{\mathrm{B}}
\end{aligned}
$$

where $V$ is the total volume of the condensate water samples treated through the exchange column; $C_{\mathrm{i}}$ and $C_{\mathrm{j}}$ are the concentrations of the anions and cations in the condensate water, respectively; $q_{\mathrm{i}}$ and $q_{\mathrm{j}}$ are the valances of the relative anions and cations; $L_{\mathrm{A}}$ and $L_{\mathrm{B}}$ are the original volumes of the anion exchange resin and cation exchange resin loaded into the reactor, respectively.

\section{Results and discussion}

The physical and chemical properties of the pre-treated ion exchange resins are summarized in Table 2 . The bulk density, moisture holding capacity and harmonic particle size of the cation exchange resin are characterized to be $808 \sim 830 \mathrm{~g} / \mathrm{L}, 41 \sim 51 \%$ and $0.6 \sim 0.8 \mathrm{~mm}$, respectively. By contrast, the anion exchange resin has a relatively low bulk density, high moisture holding capacity as well as a wide particle size distribution. As shown in Table 3, the selected activated carbon has a spherical shape and a large surface area of $1200 \mathrm{~m}^{2} / \mathrm{g}$.

Specifically, $25 \mathrm{~mL}$ of the cation exchange resin, 25 $\mathrm{mL}$ of the anion exchange resin and $150 \mathrm{~mL}$ of the mixed ion exchange resins with a cation/anion ratio of 3:5 were successively loaded into the exchange column. Besides, $64 \mathrm{~mL}$ of activated carbon was separately loaded into another tube and fixed in front of the exchange column. The treatment system was started up and purged with ultrapure water. Afterwards the condensate water sample A and B were alternatively introduced to investigate the performances of the ion exchange resins. The inlet and outlet water was regularly sampled and analyzed during the condensate water treatment experiments. As shown in Table 4, the condensate water sample A representing human metabolism wastes, had an average $\mathrm{pH}$ value of 3.4 , an average conductivity of $156.3 \mu \mathrm{S} / \mathrm{cm}$ and TOC contents around $70 \mathrm{ppm}$. However, the condensate water sample $\mathrm{B}$ representing experimental wastes, was tested to be alkaline with an average $\mathrm{pH}$ value of 9.1, and had a relatively high conductivity and TOC contents.

Table 2. The properties of ion exchange resins

\begin{tabular}{|c|c|c|c|}
\hline No. & Properties & Cation $\mathrm{H}^{+}$ & Anion $\mathrm{OH}^{-}$ \\
\hline 1 & type & H type & OH type \\
\hline 2 & bulk density (g/L) & $808 \sim 830$ & $680 \sim 730$ \\
\hline 3 & $\begin{array}{c}\text { moisture holding } \\
\text { capacity (\%) }\end{array}$ & $41 \sim 51$ & $57 \sim 67$ \\
\hline 4 & $\begin{array}{c}\text { uniformity } \\
\text { coefficient of } \\
\text { particle }\end{array}$ & $1.20 \sim 1.35$ & $1.20 \sim 1.42$ \\
\hline 5 & $\begin{array}{c}\text { harmonic mean size } \\
\text { of particle (mm) }\end{array}$ & $0.6 \sim 0.8$ & $0.3 \sim 1.2$ \\
\hline $\begin{array}{c}\text { theoretical } \\
\text { adsorption capacity } \\
\text { (eq/L) }\end{array}$ & 2.0 & 0.95 \\
\hline
\end{tabular}

Table 3. The properties of activated carbon

\begin{tabular}{|c|c|c|}
\hline No. & Properties & Parameters \\
\hline 1 & shape & spherical \\
\hline 2 & density $(\mathrm{g} / \mathrm{L})$ & 550 \\
\hline 3 & particle size $(\mathrm{mm})$ & $0.6 \sim 0.7$ \\
\hline 4 & iodine value $(\mathrm{mg} / \mathrm{g})$ & 1050 \\
\hline 5 & BET surface area $\left(\mathrm{m}^{2} / \mathrm{g}\right)$ & 1200 \\
\hline 6 & pore diameter $(\mathrm{nm})$ & $0.5 \sim 2.0$ \\
\hline
\end{tabular}

The results showed that the quality of the treated water was very stable and reached the sanitary and laboratory water standard whether on treating the condensate water sample A or B. The treated water at outlet was almost neutral with a $\mathrm{pH}$ of $6 \sim 7$ and had a conductivity even lower than $0.7 \mu \mathrm{S} / \mathrm{cm}$, indicating that most of the ionic pollutants were successfully removed by the exchange resins. The TOC content of the treated water was volatile in the range of $30 \sim 70 \mathrm{ppm}$ because that the condensate water sample A and sample B had very different organic components. According to previous experiment results, the organic acid molecules like formic acid and acetic acid could be absorbed by ion exchange resins, and some large organic molecules like caprolactam and benzyl alcohol could be absorbed by the activated carbon, while only limited amounts of the small organic molecules like acetone could be removed due to competitive effects. 
Table 4. Results of the water treatment experiments

\begin{tabular}{|c|c|c|c|c|c|c|}
\hline \multirow{2}{*}{ No. } & \multirow{2}{*}{$\begin{array}{c}\text { Cumulative } \\
\text { treated } \\
\end{array}$} & \multirow{2}{*}{$\begin{array}{c}\text { Water } \\
\text { water }(\mathrm{L})\end{array}$} & \multicolumn{2}{|c|}{$\begin{array}{c}\text { Conductivity } \\
(\mu \mathrm{S} / \mathrm{cm})\end{array}$} & \multicolumn{2}{|c|}{$\mathrm{pH}$ value } \\
\cline { 4 - 8 } & & inlet & outlet & inlet & outlet \\
\hline 1 & 5 & $\mathrm{~A}$ & 157.2 & 0.30 & 3.32 & 6.37 \\
\hline 2 & 10 & $\mathrm{~A}$ & 158.3 & 0.42 & 3.15 & 6.99 \\
\hline 3 & 15 & $\mathrm{~B}$ & 243.4 & 0.42 & 9.10 & 7.52 \\
\hline 4 & 20 & $\mathrm{~B}$ & 248.5 & 0.35 & 9.12 & 7.68 \\
\hline 5 & 25 & $\mathrm{~A}$ & 156.1 & 0.35 & 3.63 & 7.98 \\
\hline 6 & 30 & $\mathrm{~A}$ & 158.5 & 0.39 & 3.56 & 7.32 \\
\hline 7 & 35 & $\mathrm{~B}$ & 239.8 & 0.60 & 9.05 & 6.99 \\
\hline 8 & 40 & $\mathrm{~B}$ & 241.3 & 0.59 & 9.01 & 7.03 \\
\hline 9 & 45 & $\mathrm{~A}$ & 155.6 & 0.39 & 3.29 & 7.19 \\
\hline 10 & 50 & $\mathrm{~A}$ & 151.8 & 0.65 & 3.51 & 6.78 \\
\hline 11 & 55 & B & 242.3 & 0.41 & 8.98 & 7.29 \\
\hline 12 & 60 & B & 247.5 & 0.63 & 9.19 & 7.26 \\
\hline
\end{tabular}

Moreover, the effects of the types, amount ratios and the sequence of ion exchange resins were investigated using two types of condensate water samples. Five exchange columns were prepared for contrast experiments, in front of which was placed with the activated carbon column. For example, $25 \mathrm{~mL}$ of the $\mathrm{H}$ type cation exchange resin, $25 \mathrm{~mL}$ of the $\mathrm{OH}$ type anion exchange resin and $150 \mathrm{~mL}$ of the mixed ion exchange resins with a cation/anion ratio of 3:5 were successively loaded into the $1^{\text {st }}$ column. At the same amount and ratio, $\mathrm{Na}$ type cation exchange resin and $\mathrm{Cl}$ type anion exchange resin as well as their corresponding mixed resins were loaded into the $2^{\text {nd }}$ column. For the preparation of the $3^{\text {rd }}$ column, $75 \mathrm{~mL}$ of $\mathrm{H}$ type cation exchange resin and $125 \mathrm{~mL}$ of $\mathrm{OH}$ type anion exchange resin were mixed at first and then loaded. In addition, 12 $\mathrm{mL}$ of $\mathrm{H}$ type cation exchange resin, $13 \mathrm{~mL}$ of $\mathrm{OH}$ type anion exchange resin and $75 \mathrm{~mL}$ of the mixed ion exchange resins were loaded into the $4^{\text {th }}$ and $5^{\text {th }}$ columns (Table 5).

The condensate water treatment experiments over the five columns were conducted at the same conditions. When the conductivity of the treated water increased to $5.0 \mu \mathrm{S} / \mathrm{cm}$ or the $\mathrm{pH}$ value was out of the range of $5 \sim 8$, the exchange column was regarded to reach at the breakthrough point and the cumulative volume of the treated water was recorded. The results were shown in Table 5. The $\mathrm{H}$ type and $\mathrm{OH}$ type exchange resins could treat more condensate water than the $\mathrm{Na}$ type and $\mathrm{Cl}$ type resins. The amount ratios and sequence of ion exchange resins also have significant effect on the water treatment performance. The total volume of treated water over the $3^{\text {rd }}$ column was nearly $20 \%$ lower than that over the $1^{\text {st }}$ column, indicating that the application of complex beds could improve the treated water quality and use the loaded resins more efficiently. The total volume of treated water over the $4^{\text {th }}$ and $5^{\text {th }}$ columns which were successively connected was similar to that over the $1^{\text {st }}$ column, indicating that effects of resin layer resistance and diffusion are limited at the current scale. Therefore, the above results revealed the original performance of the exchange resins, but scale-up problems should be carefully considered in industry.

Table 5. The effects of the types, amount ratios and the sequence of ion exchange resins

\begin{tabular}{|c|c|c|c|c|}
\hline \multirow{2}{*}{$\begin{array}{l}\text { Column } \\
\text { No. }\end{array}$} & \multicolumn{3}{|c|}{ Loaded resins $(\mathrm{mL})$} & \multirow{2}{*}{$\begin{array}{c}\text { Treated } \\
\text { water } \\
\text { (L) }\end{array}$} \\
\hline & cation & anion & mixed & \\
\hline $1^{\text {st }}$ & 25 & 25 & 150 & 50 \\
\hline $2^{\text {nd }}$ & $25 / \mathrm{Na}$ & $25 / \mathrm{Cl}$ & $\begin{array}{c}150 / \mathrm{Na}- \\
\mathrm{Cl}\end{array}$ & 33 \\
\hline $3^{\text {rd }}$ & 75 & 125 & - & 42 \\
\hline $4^{\text {th }}$ & 12 & 13 & 75 & \multirow{2}{*}{46} \\
\hline $5^{\text {th }}$ & 12 & 13 & 75 & \\
\hline
\end{tabular}

Furthermore, under the actual operating conditions, the continuous dynamic test was carried out on a condensate water treatment module consisting of two adsorption columns and four exchange columns to evaluate its real service life. The results are shown in Figure 2. It showed that the treated water quality was very stable. According to the equations (1) and (2), the saturated adsorption capacities of the basic anion exchange resin and the acidic cation exchange resin are calculated and listed in Table 6 . In addition, the treated water was further analyzed to find out that the basic anion exchange resin first reached at the breakthrough point because of the higher concentration of anions in the condensate water.
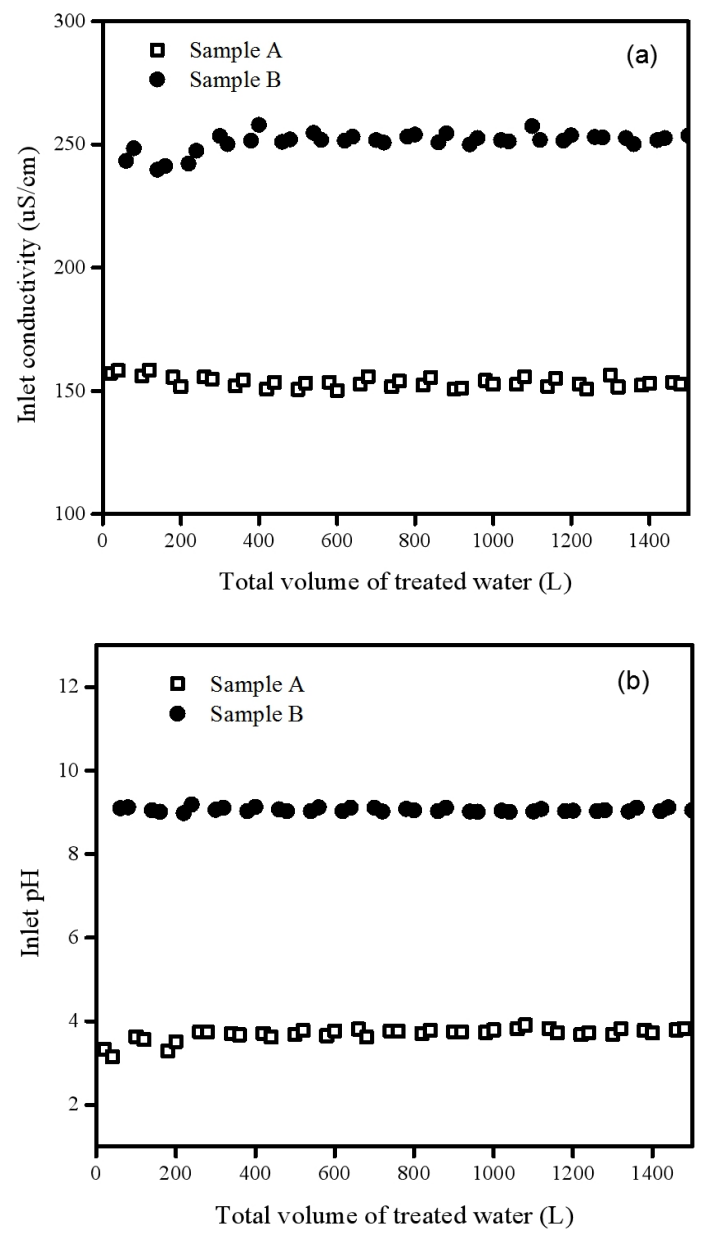

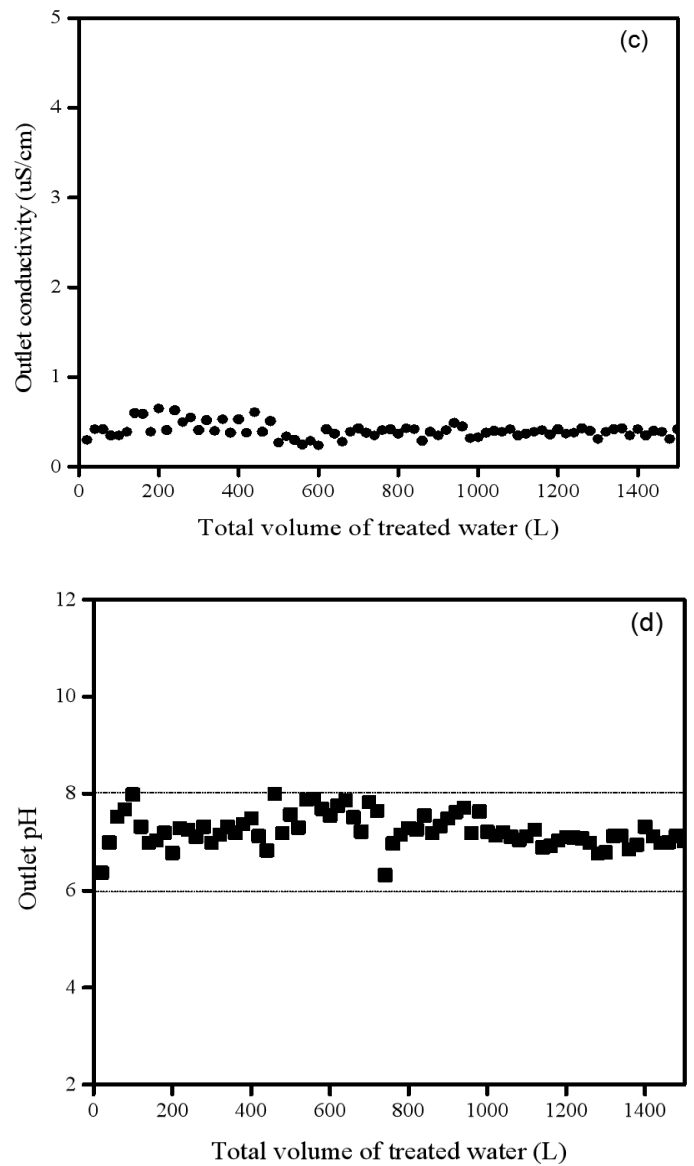

Fig.2. The water conductivity and $\mathrm{pH}$ value versus the total volume of treated water.

Table 6. The adsorption capacity of exchange resin

\begin{tabular}{|c|c|c|}
\hline No. & Exchange resin & $\begin{array}{c}\text { Adsorption } \\
\text { capacity }(\mathrm{mol} / \mathrm{L})\end{array}$ \\
\hline 1 & basic anion exchange resin & 0.87 \\
\hline 2 & acidic cation exchange resin & 1.82 \\
\hline
\end{tabular}

\section{Conclusions}

In this work, a novel integrated process of ion exchange resins and activated carbon is proposed for the advanced treatment of condensate water either from laboratories or human metabolism wastes. A fixed bed column of selfpre-treated basic anion exchange resin, acidic cation exchange resin, mixed ion exchange resins and modified activated carbon was applied to remove ionic pollutants, organic pollutants and adjust the $\mathrm{pH}$ value of output water. The treated water was almost neutral with a $\mathrm{pH}$ of $5 \sim 8$ and had a conductivity lower than $5.0 \mu \mathrm{S} / \mathrm{cm}$ as well as a TOC content in the range of $30 \sim 70 \mathrm{ppm}$, indicating that most of the pollutants were successfully removed by the exchange resins. The saturated adsorption capacities of the basic anion exchange resin and the acidic cation exchange resin were estimated to be $0.87 \mathrm{~mol} / \mathrm{L}$ and 1.82 $\mathrm{mol} / \mathrm{L}$, respectively, which were higher than commercial ones. The effects of types, amount ratios and sequence were also investigated. Moreover, continuous dynamic test showed that the treatment module consisting of two adsorption columns and four ion exchange columns had good performances on the advanced treatment of both kinds of condensate water, and the treated water quality was stable. The results will help the design of water recovery units for practical application in the future.

\section{Acknowledgments}

We acknowledge the technical support by the Beijing Engineering Research Center of Space Water and Gas Purification and Regeneration. We also thank Prof. X.Y. Liang for materials preparation.

\section{References}

1. K. J. Loveless, A. Farooq, N. Ghaffour, Water Resources Management 27, 1351 (2013).

2. I. Noor, A. Martin, O. Dahl, Chemical Engineering Journal 399, 125707 (2020).

3. L. Wang, Z. F. Zhu, IOP Conference: Materials Science and Engineering 711, 012104 (2020).

4. H. Zangeneh, A. A. L. Zinatizadeh, M. Feyzi, S. A. Habeeb, K. Farokhi, Journal of Environmental Chemical Engineering 2, 2327 (2014).

5. E. Korzhova, O. V. Kuznetsova, A. N. Smagunova, M. V. Stavitskaya, Journal of Analytical Chemistry 66, 222 (2011).

6. N. Barati, M. M. Husein, J. Azaiez, Journal of Membrane Science 617, 118641 (2021).

7. L. Chen, Y. Xue, T. Luo, F. Wu, A. N. Alshawabke, Chemical Engineering Journal 403, 126278 (2021).

8. M. K. Chan, N. Abdullah, E. H. A. Rageh, P. Kumaran, Y. S. Tee, Separation and Purification Technology 254, 117612 (2021).

9. S. Raghuvanshib, V. Bhakara, C. Sowmyab, K. S. Sangwana, The 24th CIRP Conference on Life Cycle Engineering 61, 761 (2017).

10. D. H. Kim, J. H. Cha, S. H. Hong, D. Y. Kim, C. W. Kim, Korean Journal of Chemical Engineering 26, 90 (2009).

11. M. D. Victor-Ortega, J. M. Ochando-Pulido, D. A. Rodriguez, A. Martinez-Ferez, Journal of Industrial and Engineering Chemistry 34, 224 (2016).

12. J.S. Wang, X. Y. Liang, G. Z. Cui, J. D. Li, C. J. Zhao, S. L. Yang, Space Medicine \& Medical Engineering 28, 53 (2015). 